\title{
Comparative investigation of single-phase Distributed Grid- connected with and without D-STATCOM
}

\author{
Kalagotla Chenchireddy ${ }^{1 *}$, Khammampati $R$ Sreejyothi ${ }^{2}, V$ Kumar $^{3}$ \\ ${ }^{1,2,3}$ Department of EEE, Teegala Krishna Reddy Engineering College, Hyderabad, India
}

\begin{abstract}
Power quality becomes one of the significant contemplations in the power system. It has become significant particularly with the presentation of advanced devices. These high-level advanced devices are sensitive to the nature of the power supply. The power quality refers to the voltage, current, and frequency at the evaluated value. If any variation occurred in these quantities the standard rating is considered as the power quality problem. The power quality issues like loss of sine, voltage sag, voltage swell, short interruption, long interruption, flicker, and harmonics. To overcome these power quality issues, we like to utilize custom power devices on the distribution side. Among various custom power devices, Distribution Static Synchronous Compensator is liked to use for expanding the power quality, on account of their basic power supply at the circulation power system which can't be interfered with development and less complexity. This paper presents the near research of single-phase with and without D-STATCOM by utilizing MATLAB Simulink programming.
\end{abstract}

\section{Introduction}

In these modern trends, the quality of power and its requirement has been increased rapidly. There are many ways to generate the power but there are few issues are occurred like poor voltage regulation, harmonics, purity of sine wave is lost and disturbances occurring on the distribution side. The injection of extreme reactive power increases the ohmic losses and reduces the active power in the distribution system. There should be a continuous distribution system. This can be accomplished through convention power devices. One of the convention power devices is a static Synchronous compensator at the distribution side known as DSTATCOM.

A definitive objective of applying a shunt compensator is to build the transmission power in a transmission system. By utilizing power electronic gadgets likewise, we can accomplish voltage guidelines by considering some custom power devices like D-STATCOM. These custom power devices giving power quality on the distribution side. D-STATCOM is shunt associated device and in addition one of the strategies for the static coordinated compensator. These voltage guidelines are for the most part for delicate burdens that might be strongly influenced by fluctuations in the power system voltage. This can be settled by utilizing a custom force power device like D-STATCOM.

Corresponding Author: ${ }^{1}$ chenchireddy.kalagotla@gmail.com
Power quality is the main concern for utilities and clients. Power quality issues mostly incorporate voltage and current awkwardness, flashing, sounds, and force interference. These power quality issues can make the hardware work unusually. The exhibition of DSTATCOM relies upon the control calculation used to remove the reference current part. Contrasted with SVC, DSTATCOM enjoys many benefits. They have a quick reaction time, occupy less room, and wipe out music. DSTATCOM has the best presentation under low voltage conditions because the responsive current can be kept consistent. [1]-[2] DSTATCOM is a device connected in parallel to alleviate power quality problems in the flow. There are many control technologies for the parallel compensator control of the three-phase four-wire system. This article introduces five control technologies, which are model predictive control, STATCOM based on slider mode controller, ANFISLMS-based control, synchronous reference system theory, and new algorithms based on Adaline. [3]-[4] The Instantaneous power theory proposed for DSTATCOM is combined with HCC adaptive control. The proposed controller acts as an active power filter and reduces source current harmonics, thereby improving power quality. The proposed controller maintains an almost uniform power factor. The THD of the current source is reduced and maintains the IEEE519 standard. [5]-[6] In the power grid, common problems are harmonics and reactive power caused by nonlinear loads. Active power filter based on adaptive hysteresis current 
control is implemented to improve the power quality in the power grid. The proposed controller eliminates harmonics and compensates for reactive power in the distribution system. The power supply current becomes sinusoidal and in-phase through the main power supply voltage. Reduce the THD of the current source and maintain the IEEE519 standard [7] Voltage dips and surges are the most common power quality problems in medium and low voltage distribution networks. These problems are alleviated by using dynamic voltage recovery (DVR). [8] DVR can monitor balance and imbalance without any difficulty and perform self-injection.

\section{D-STATCOM Topology}

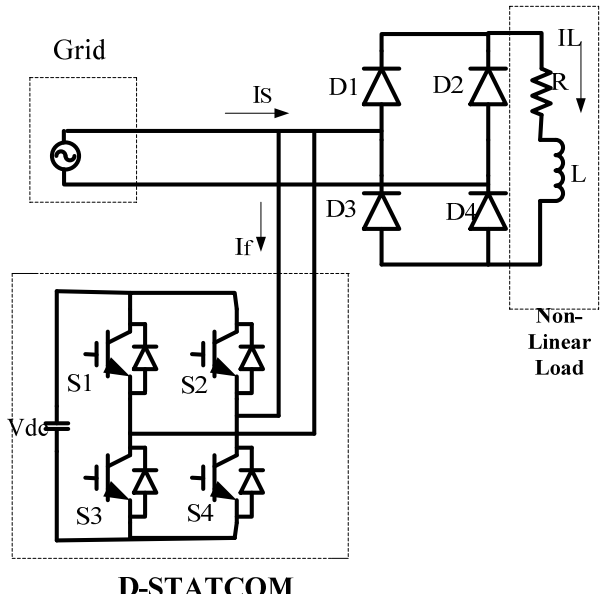

Fig .1. Schematic diagram of single-phase distributed grid-connected with D-STATCOM

DSTATCOM is a fast-response solid-state power electronic converter based on parallel controlled voltage source converter (VSC), which can inject current into utility feeders or nodes in power distribution systems to achieve smooth reactive power compensation, thereby improving DS Power quality, such as improving voltage distribution and minimizing DS power loss [9]-[10]. It is mainly composed of an inverter, and its working principle is to switch automatic control. The output voltage of DSTATCOM can be controlled as indicated by receptive power prerequisites since it is a voltage converter. DSTATCOM at the end of the day is a conveyed static synchronization capacitor (DSTATCOM). Typically the gadget is upheld by DC energy stockpiling capacitors. It produces inductive and capacitive receptive force as per load prerequisites to meet the determinations of public organizations [10].

\subsection{Components involved in DSTATCOM design}

The DSTATCOM comprises an IGBT based VSC (voltage source converter), DC stockpiling capacitor, and a coupling transformer as displayed in Fig. 1

1) VSC: VSC is utilized to change over the DC input voltage to an $\mathrm{AC}$ output voltage at crucial recurrence and creates or retains the reactive power.

2) DC storage capacitor or energy storage device: DC storage is utilized to supply consistent DC voltage to the voltage source converter (VSC) through a DC interface capacitor for the age of infused voltages.

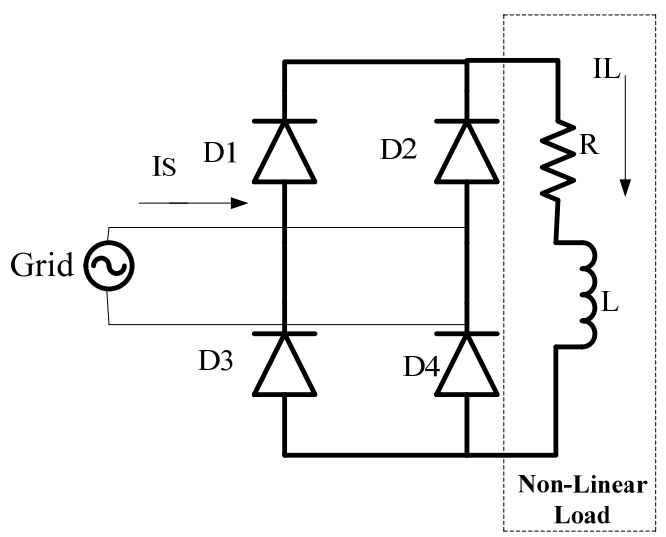

Fig.2.Schematic diagram of single-phase distributed grid-connected without D-STATCOM

The above figure. 2 shows the schematic figure without D-STATCOM. This schematic diagram consists of a single AC supply source, diode bridge rectifier, and the non-linear load connected. The rectifier circuit having four diodes and resistive and inductive load. When the non-linear load in distribution side power quality is disturbed. The power quality disturbances are voltage swell, voltage sag, voltage notch, harmonics, transient, and flicker. This paper presents D-STATCOM for improving power quality in the distribution system.

D-STATCOM is one of the custom power devices and also one of the methods STATCOM (STATIC SYNCHRONOUS COMPENSATOR). When the STATCOM is placed at the Distribution level is known as D-STACOM (DISTRIBUTION STATCOM). Usually in the D-STATCOM DC capacitor is connected in parallel with the voltage source converter. By placing D-STATCOM in the power system helps to solve the power outages in industries, improves voltage regulation, and also elimination of harmonics.

\section{Controller strategy}

The controllers that are used in this project are PI and PR controllers. 


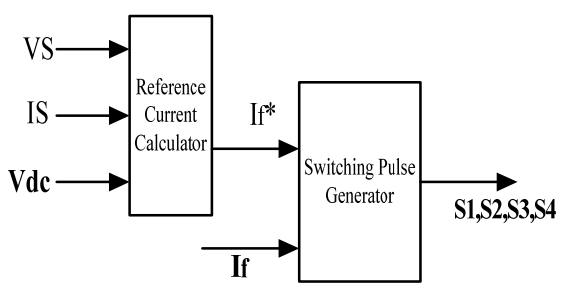

Fig. 3 PI Controller for DSTATCOM

\subsection{PI Controller}

PI Controller is a response control loop that calculates a fault signal by taking the variation of a system. We had used the PI controller 2 times with different circuits. The first PI controller is used in a phase-locked and inn controller circuit. In a phaselocked loop, the PI controller is used to have a certain transfer function; which is taking the difference between alpha, constant, and beta. The setpoint of the transfer function will give the active and reactive power as output. And another PI controller was used in the controller circuit, which calculates a fault signal taking the variation of voltage across the RC load and the constant. It will help the PR controller for getting efficient results.

Point out that because of the intricacy of the electronic parts inside the circuit way. Having an exchange capacity would have permitted reenacting the framework in software is critical to call attention to that because of the intricacy of the electronic parts inside the circuit way. Having an exchange capacity would have permitted reproducing the framework in a product bundle, for example, MATLAB/Simulink, and helping me in tracking down the right relative and essential consistent boundaries for the controller. are bundle like MATLAB/Simulink and helping me in tracking down the right corresponding and indispensable steady boundaries for the regulator.

\subsection{PR Controller}

A corresponding proportion resonance (PR) regulator is utilized for the traditional relative vital proportion integral (PI) regulator in this power system. By correlation with the regular PI control strategy, the PR control can present a limitless addition at the central recurrence and thus can accomplish zero consistent state mistakes.

Moreover, a pseudo-coordinated $\mathrm{d}-\mathrm{q}$ change is utilized in the current control plot and an all-pass channel-based single-phase computerized phaselocked loop (PLL) is acquainted with distinguishing the period of lattice voltage. Recreation and test confirm the superior of the carried out control conspire.

\section{Comparisons between Simulink Design of with D-Statcom and Without D-Statcom}

Here first we will see the power circuit of both designs. In this design, the ac grid is taken ac supply for both the designs but there is a common difference between these two designs that is; for with D-STATCOM we had used inverter bridge consists of 4 IGBT and when it comes to Without DSTATCOM the rectifier bridge was used with 4 thyristors. All other controller circuits, PLL operations are the same for both the designs, and working is experienced is mentioned in the block diagrams. The two IGBT switches will operate in a one-half cycle and the other two switches will operate in another half cycle, which performs a full cycle operation.

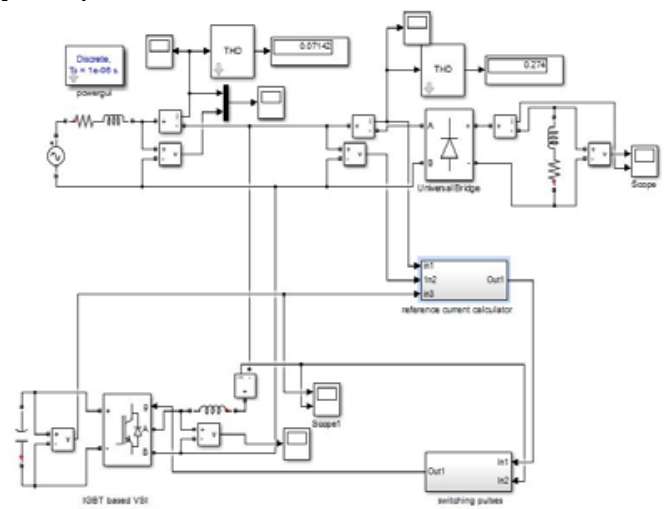

Fig 4. Simulink design with D-STATCOM

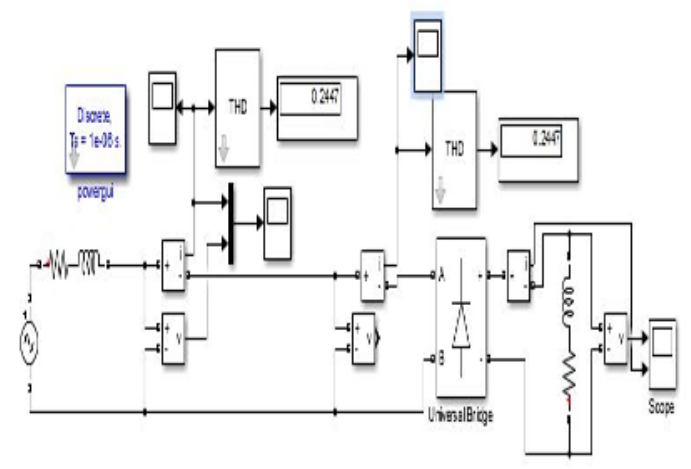

Fig 5. Simulink design without D-STATCOM

\section{Comparison Between With \& Without D-Statcom Waveforms}

\subsection{Waveforms of With D-Statcom}

Below figures 6(a), 6(b) and 6(c) show the waveforms of D-STATCOM. From below fig 6(a), the VGRID is in phase with the IGRID. The inverter current IINV has raised to a peak value because of placing interference inductor between Inverter 
Bridge and input. This will reduce the current harmonics that you can see in below fig 6(a) ILOAD the load current has gained the pure sine wave in DSTATCOM. The waveform of VDC is not having any disturbances that you can observe in fig 6(c), due to the placing of the shunt capacitor across the inverter bridge.

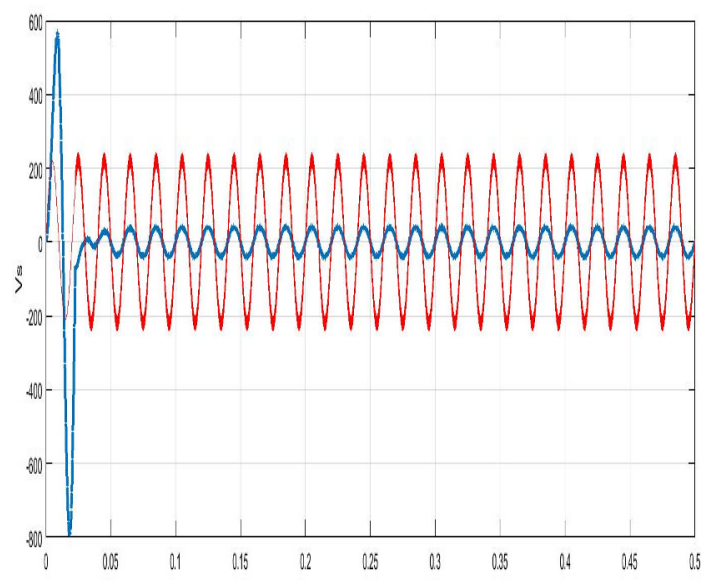

Fig. 6(a) waveforms of VGRID, IGRID of with DSTATCOM
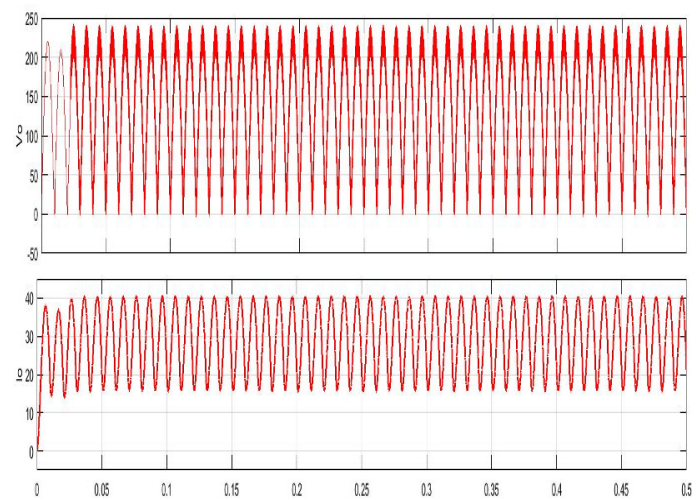

Fig. 6(b) waveforms of output voltage and current of with D-STATCOM

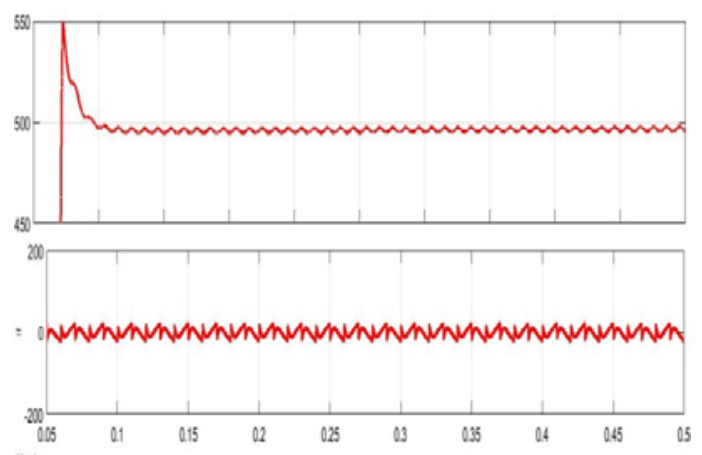

Fig .6(c) waveforms of injected current and DC capacitor voltage of with D-STATCOM

\subsection{Waveforms of without D-Statcom}

Fig 6(d) shows the waveforms without DSTATCOM of VGRID, IGRID. From fig 6(c) VGRID and IGRID are not in phase, ILOAD having a small value compared to that of D-STATCOM. Fig 6 (e) shows the waveform of VDC, which is having disturbances during the one complete cycle. The non-linear load having some delays in the cycle without D-STATCOM, this can be rectified with DS-STATCOM. The main disadvantage of this circuit not having a custom power device, which leads to having linear balanced loads and will have a sine wave as output.

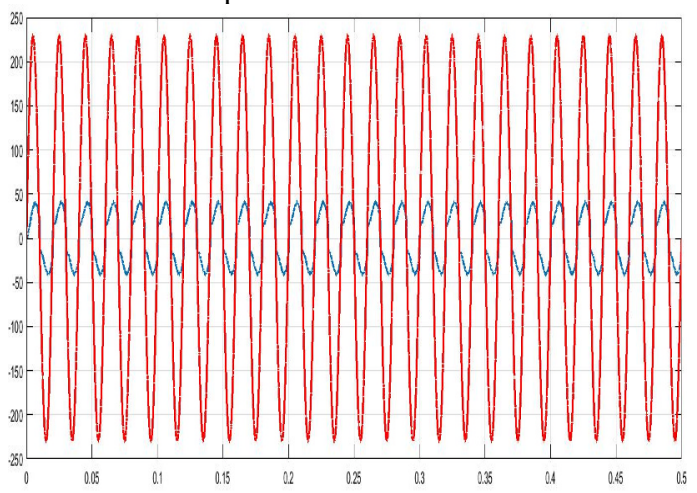

Fig 6.(d) waveforms of VGRID, IGRID of without DSTATCOM
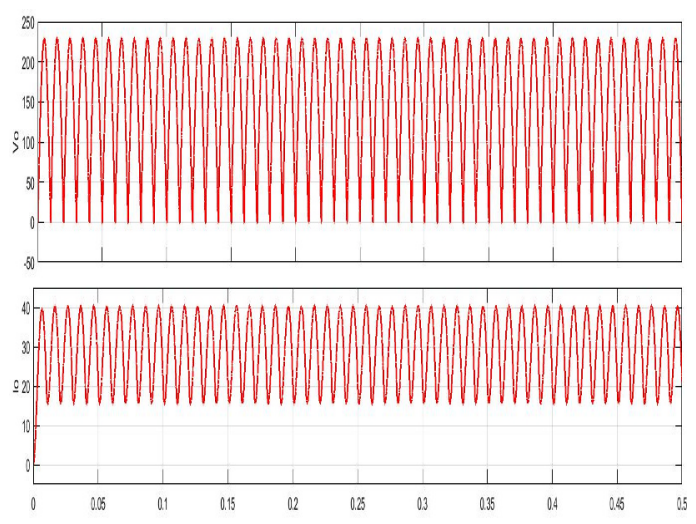

Fig. 6(e) waveform of output voltage and current of without D-STATCOM

Table 1. Comparison table of with \& without d-statcom

\begin{tabular}{|c|c|c|c|}
\hline $\begin{array}{l}\text { With D- } \\
\text { STATCOM }\end{array}$ & $\begin{array}{l}\text { VGRID } \\
\text { Is In } \\
\text { Phase } \\
\text { With } \\
\text { IGRID }\end{array}$ & $\begin{array}{l}\text { ILOAD } \\
\text { Has A } \\
\text { Sufficient } \\
\text { Value }\end{array}$ & $\begin{array}{l}\text { VDC No } \\
\text { Disturbances } \\
\text { In Waveform }\end{array}$ \\
\hline $\begin{array}{l}\text { Without D- } \\
\text { STATCOM }\end{array}$ & $\begin{array}{c}\text { VGRID } \\
\text { Is Not In } \\
\text { In Phase } \\
\text { With } \\
\text { IGRID }\end{array}$ & $\begin{array}{c}\text { ILOAD } \\
\text { Has A } \\
\text { Small } \\
\text { Value }\end{array}$ & $\begin{array}{c}\text { VDC } \\
\text { Disturbances } \\
\text { In Waveform }\end{array}$ \\
\hline
\end{tabular}




\section{Conclusion}

In this paper, the examination between with DStatcom and without D-Statcom is represented by utilizing MATLAB/SIMULINK programming. The outcome obtained from the simulation shows that it is more interesting for custom power devices to work on the nature of the power. The exhibition with DStatcom and without D-Statcom to further develop the voltage guideline, are completed in simulation software adequately. By considering the outcomes from this work at long last we can conclude that DSTATCOM shows better productivity and capability on voltage guideline, pure sine wave, and in addition to various types of fault compensation when connected with D-Statcom. The THD in the current waveform is $0.24 \%$ without D-Statcom and The THD in the current waveform is $0.07 \%$ with DStatcom

\section{References}

1. Chenchireddy, K, V. Jegathesan, and L. Ashok Kumar." Innovations in Electrical and Electronics Engineering (2020): 35-43.
2. Chenchireddy, K, and V. Jegathesan." Inventive Communication and Computational Technologies (2021): 961-971.

3. Chenchireddy, Kalagotla, V. Kumar, and Khammampati R. Sreejyothi. 2021 7th International Conference on Advanced Computing and Communication Systems (ICACCS). Vol. 1. IEEE, 2021.

4. Chen, C. S., Lin, C. H., Hsieh, W. L., Hsu, C. T., \& Ku, T. T. (2013). IEEE Transactions on Power Systems, 28(2), 1560-1567.

5. Srikakolapu, J. (2021). CPSS Transactions on Power Electronics and Applications, 6(1), 5262.

6. Karanki, S. B., Geddada, N., Mishra, M. K., \& Kumar, B. K. (2012). IEEE Transactions on Power Electronics, 27(3), 1201-1211.

7. Elnady, A., \& Salama, M. M. A. (2005). IEEE Transactions on Power Delivery, $20(2$ I), 9921000.

8. Ghosh, A., \& Ledwich, G. (2003). IEEE Transactions on Power Delivery, 18(4), 13021309.

9. Sydu, Shabbier Ahmed, K Chenchireddy, and K R. Sreejyothi. Available at SSRN 3852706 (2021)

10. Kumar, C., \& Mishra, M. K. (2014). IEEE Transactions on Industrial Electronics, 61(12), 6517-6527. 